\title{
ORGANIZACIÓN, MOVILIZACIÓN Y ACCIÓN FAMILIAR Y FEMINISTA ANTE \\ EL FEMICIDIO EN AMÉRICA LATINA
}

\section{Esther Pineda $\mathbf{G}^{1}$}

Resumen: El femicidio es el asesinato sexista y misógino de una mujer, el cual tiene lugar en el contexto de relaciones de poder, dependencia y desigualdad. Según las estadísticas oficiales de 16 países de América Latina, entre los años 2005 a 2018 se han registrado 13438 femicidios, sin embargo, pese a su gravedad y recurrencia, estos asesinatos aun gozan de aceptación social, continúan siendo justificados en los medios de comunicación, y persisten altos índices de impunidad, negligencia e inacción institucional ante su ocurrencia. Este hecho ha creado las condiciones para la organización y movilización de las familias de las víctimas de femicidio, cuyo accionar ha permitido su visibilización, ha llamado la atención de los medios de comunicación, ha permitido la contabilización de los crímenes, ha convocado a los organismos internacionales, ha comprometido al movimiento feminista, ha logrado la tipificación del delito, pero principalmente continúa demandando justicia.

Palabras clave: Violencia contra la mujer, Femicidio, Familias, Movimiento feminista, América Latina.

\footnotetext{
1 Universidad Central de Venezuela. Socióloga (2010), Magíster Scientiarum en Estudios de la Mujer Mención Honorífica (2013), Doctora en Ciencias Sociales Mención Honorífica (2015) y Postdoctora en Ciencias Sociales (2017) egresada de la Universidad Central de Venezuela. Autora del libro "Cultura femicida. El riesgo de ser mujer en América Latina" (2019).
} 
Resum: El femicidi és l'assassinat sexista i misogin d'una dona, el qual té lloc en el context de relacions de poder, dependència i desigualtat. Segons les estadístiques oficials de 16 països d'Amèrica Llatina, entre els anys 2005 i 2018 s'hi han registrat 13.438 femicidis; no obstant això, malgrat la gravetat i la recurrència, aquests assassinats encara gaudeixen d'acceptació social, continuen sent justificats en els mitjans de comunicació i continuen haventhi alts índexs d'impunitat, negligència i inacció institucional davant de la seva ocurrència. Aquest fet ha creat les condicions per a l'organització i la mobilització de les famílies de les víctimes de femicidi, les accions de les quals han permès la visibilització de la problemàtica, han cridat l'atenció dels mitjans de comunicació, han permès la comptabilització dels crims, han convocat els organismes internacionals, hi han compromès el moviment feminista, han aconseguit la tipificació del delicte però, principalment, continuen demandant justícia.

Paraules clau: violència contra la dona, femicidi, famílies, moviment feminista, Amèrica Llatina

Abstract: Femicide is the sexist and misogynistic killing of a woman, which takes places in the context of power relations involving dependency and inequality. According to official statistics from 16 Latin American countries, between 2005 and 2018, 13,438 femicides were recorded. However, despite the seriousness and recurrence of this type of murder, they still enjoy social acceptance; they are still justified in the media, and there are still high rates of impunity, negligence and inaction surrounding their occurrence. This fact has established the conditions for the organization and the mobilization of the families of femicide victims, whose actions have brought greater visibility to the problem, have attracted media attention, have fostered the counting of this type of murder, have drawn in both international organizations and the feminist movement, have attained a legal definition of the crime but, above all, are still demanding justice for the victims.

Keywords: violence against women, femicide, families, feminist movement, Latin America 


\section{Femicidio: escenarios, manifestaciones y destinatarias}

El término femicidio fue introducido por la feminista sudafricana Diana Russell en el año 1976 y progresivamente enriquecido durante la década de los 90 para explicar "el asesinato de mujeres por hombres porque son mujeres" (Russell, 2006, p. 101). De acuerdo a ello, el femicidio puede entenderse como la figura lingǘstica y jurídica que permite definir y categorizar el asesinato de mujeres en el contexto de relaciones de poder, dependencia y desigualdad; crímenes que siempre son cometidos por hombres, los cuales se arrogan derechos sobre el cuerpo de las mujeres o que creen que ellas son de su propiedad.

Una de las principales formas en las que se manifiesta este tipo de crímenes es a través del femicidio íntimo, el cual supone el asesinato de mujeres perpetrado por novios, ex novios, concubinos, ex concubinos, esposos, ex esposos, amantes, ex amantes, o cualquier otro hombre con quien la victima mantenía o mantuvo en algún momento de su vida una relación de carácter sexo-afectiva. Estos hombres generalmente asesinan a las mujeres cuando ellas dan muestras de independencia, autonomía y empoderamiento, comienzan a cuestionar y desafiar el mandato masculino, comienzan o retoman estudios y trabajo, frecuentan amigas o familiares, toman conciencia de las formas de violencia que viven dentro del hogar, planean separarse, han expresado su deseo de terminar la relación o se niegan a reanudar el vínculo afectivo y sexual que previamente habían terminado.

Los femicidios también son cometidos por hombres miembros del grupo familiar, entre sus perpetradores destacan los padres, padrastros, tíos, hermanos, abuelos y primos de las niñas y las mujeres, en el contexto de los denominados crímenes de honor; estos crímenes son cometidos como un acto de afirmación de la autoridad masculina cuando las niñas y mujeres han desafiado o trasgredido la tradición familiar o cultural, cuando se niegan a que les sea impuesta la voluntad de los hombres de la familia, o cuando no responden a las expectativas y exigencias de feminidad. Pero estos asesinatos 
de niñas y mujeres también son perpetrados por los hombres de su grupo familiar durante la comisión u ocultamientos de la violencia incestuosa, modalidad bajo la cual se suelen cometer la mayor cantidad de femicidios de niñas y adolescentes por su condición de vulnerabilidad, proximidad y dependencia con respecto a sus agresores.

Los femicidios también son cometidos contra niñas y mujeres en el contexto de la violencia sexual, ya sea por parte de hombres conocidos en posición de autoridad como médicos, maestros, entrenadores, jefes, o perpetrados por hombres cercanos a la víctima por su proximidad en entornos familiares, comunitarios, académicos o laborales; por ejemplo, hombres amigos de la familia que frecuentan el hogar, vecinos, comerciantes cercanos a la comunidad, compañeros de estudio o de trabajo, amigos o conocidos en general.

Estos femicidios de carácter sexual también son perpetrados por hombres con quienes la víctima no tenía ningún tipo de vínculo, hombres que la niña o la mujer no conocía, que nunca había visto en su vida, con quien nunca había intercambiado palabras o coincidido en algún espacio, pero que, durante su salida o regreso de su casa, el colegio, el trabajo, una tienda, una fiesta, cuando tomaba un taxi u otro tipo de transporte público, las siguieron, sometieron o encerraron para ser violadas y asesinadas. En oportunidades estos crímenes son ejecutados en la vía pública, algunas de estas víctimas son encerradas en alguna vivienda o establecimiento, mientras que otras son llevadas hacia algún paraje lejano o terreno baldío donde sus cuerpos sin vida suelen ser abandonados.

También abundan los femicidios perpetrados en el contexto de la trata y la explotación sexual. Algunas niñas y mujeres sometidas a la explotación y comercialización de sus cuerpos, explotadas en las calles o prostíbulos, son asesinadas por los hombres consumidores de prostitución durante las violaciones, pero también por parte los proxenetas y tratantes. Estos asesinatos tienen lugar durante los intentos de escape de las víctimas, crímenes que se consolidan como un acto de afirmación del poder frente a 
otras niñas y mujeres explotadas, como aleccionamiento e intimidación contra aquellas que intenten desafiar la autoridad de los explotadores; no obstante, estos asesinatos también son consumados por los proxenetas y tratantes cuando las mujeres explotadas sexualmente dejan de ser consideradas "rentables", útiles y comercializables, ya sea por su edad, por la existencia de alguna enfermedad, o ante cualquier otra situación que amenace el negocio de la explotación.

Así mismo, las mujeres son asesinadas por conocidos o desconocidos cuando su preferencia sexo-afectiva desafía el mandato de la feminidad, es decir, cuando son lesbianas o bisexuales. Estas mujeres también son asesinadas por el hecho de ser mujeres en el contexto de las otras modalidades anteriormente descritas, pero en este caso se hace referencia solo a aquellos crímenes específicos que tienen como móvil la preferencia sexo-afectiva de la víctima, motivación además que enfrenta dificultades para ser identificada y sistematizada como tal, a menos que, el victimario durante el ataque haya manifestado de forma explícita sus motivaciones o dejado alguna prueba que dé cuenta del carácter del referido crimen.

En todos estos casos, con independencia de su tipología o manifestación, la motivación es siempre el sexismo y la misoginia. El odio a las niñas y a las mujeres; pero también, como expresión del deseo de poder, posesión, afirmación, control y dominio de sus cuerpos, considerados objetos al servicio y propiedad masculina. Este hecho pone en evidencia que los hombres matan a las mujeres porque quieren, pero sobre todo porque pueden, debido a la institucionalización de una cultura femicida, la cual puede ser definida como:

Aquella que subvalora la vida de las mujeres en relación a la vida de los hombres, en la que se les concibe como prescindibles, pero sobre todo, sustituibles. Una cultura femicida es aquella donde se acepta, naturaliza y justifica el asesinato de mujeres por el hecho de ser mujeres, donde se permite su asesinato, se deja que ocurra con 
beneplácito, o se encubre garantizando su impunidad (Pineda, 2019, p. 63).

Cultura femicida que envía a los hombres el mensaje de que las vidas de las mujeres pueden ser tomadas y terminadas por ellos cuando lo deseen porque, dada su naturaleza y destinatarias estos son los crímenes menos repudiados socialmente, menos perseguidos policialmente y menos condenados penalmente.

\section{La lucha contra el femicidio: De las familias de las víctimas a bandera feminista}

Los asesinatos de mujeres motivados por el sexismo y la misoginia han estado presente en las diferentes etapas del proceso histórico social, en las diferentes épocas y en las diferentes formas organizativas que hasta ahora conocemos; sin embargo, pese a que fue conceptualizado desde la década de los 70 por Diana Russell y, esta durante los años 90 a través de sus escritos intentó posicionar el concepto a fin de politizar estos crímenes, no tuvo mucho impacto y aceptación; por ello, en su libro Femicide in global perspective (Femicidio: Una perspectiva global) afirmaría:

Desafortunadamente, muchas feministas, incluidas activistas contra la violencia hacia las mujeres, tampoco reconocen las políticas sexuales del femicidio. De las muchas manifestaciones y marchas contra la violencia hacia las mujeres en las cuales he participado, sólo en dos o tres se ha incluido al femicidio o al asesinato de mujeres en los cantos y las consignas. Dado que muchas feministas ignoran el femicidio, difícilmente puede sorprendernos que las no feministas fallen en reconocer la naturaleza política de la mayoría de los asesinatos de mujeres. Esta severa laguna en la conciencia feminista es particularmente irónica, dado que los femicidios son la forma más extrema de violencia misógina contra las mujeres. (...) La poca familiaridad de muchas feministas con este término puede explicar también por qué las tan dispares campañas feministas organizadas 
para combatir el femicidio en Estados Unidos y en otras partes no han logrado conseguir que las diferentes corrientes del movimiento contra la violencia hacia las mujeres incluyan sistemáticamente el asesinato de mujeres en sus agendas. (...) Hasta que las feministas se den cuenta de que existe un término que se aplica a los asesinatos de mujeres por-ser-mujeres, probablemente no reconocerán el vínculo entre los diversos tipos de femicidio ni se embarcarán en una campaña concertada para protestar y tratar de prevenir los femicidios (Russell, 2006, p. 63-65).

El interés y movilización ante estos crímenes, no llegó como lo había pronosticado Russell con la toma de conciencia de la existencia de un término que los explicase, pero la masividad de estos asesinatos de mujeres por el hecho de ser mujeres, si impulsaron el interés por comprenderlos, conceptualizarlos, denunciarlos, sistematizarlos, tipificarlos y sancionarlos. Fue entonces la masividad, sistematicidad y crueldad de los brutales y sexualizados asesinatos de mujeres registrados en Ciudad Juárez, en el Estado mexicano de Chihuahua durante la década de los 90, lo que despertó las alarmas de las familias, las comunidades, activistas, académicas y medios de comunicación; convirtiendo a México en el foco de atención y preocupación ante la emergencia e incremento de crímenes muy específicos contra las niñas y las mujeres.

De acuerdo a Labrecque (2005) en agosto de 2003 Amnistía Internacional daba cuenta de la ocurrencia de 370 casos de mujeres asesinadas desde 1993 en Ciudad de Juárez y más de 400 mujeres desaparecidas; mientras que, según señala Marcela Lagarde en su ensayo Antropología, feminismo y política: Violencia feminicida y derechos humanos de las mijeres (2008), la Procuraduría General de la República reportó que en el lapso de 12 años entre 1993 y 2005 fueron asesinadas por homicidios dolosos en Ciudad Juárez Chihuahua, 379 niñas y mujeres. De estas según señala Griselda Gutiérrez Castañeda en el libro Violencia sexista. Algunas claves para la comprensión del feminicidio en Ciudad Juárez, por lo menos en 137 casos hay evidencia de 
violencia sexual y existe un registro aproximado de 500 mujeres desaparecidas.

Una cantidad importante de estas niñas y mujeres fueron halladas golpeadas, estranguladas, asfixiadas, acuchilladas, baleadas, torturadas, mutiladas, desmembradas e incineradas; y se ha especulado que los responsables de estos asesinatos son violadores y asesinos seriales, tratantes de personas y proxenetas, productores de películas snuff, traficantes de órganos, carteles de drogas, pandilleros, pero también políticos, funcionarios y policías corruptos.

Estos crímenes comenzaron a ser denunciados y visibilizados por sus dolientes, es decir, por los familiares de las víctimas (principalmente madres) $)^{2}$, quienes se movilizaron para exigir explicaciones a las autoridades por los crímenes cometidos contra sus hijas, para exigir la investigación expedita y sin dilaciones, para demandar la identificación, persecución y encarcelamiento de los responsables y, para pedir justicia y condenas justas contra los perpetradores. Sin embargo, nada de esto paso y los cuerpos de las niñas y mujeres en Ciudad Juárez se fueron acumulando, las cifras se fueron incrementando, y quedó en evidencia que la vida de las niñas y mujeres en Ciudad Juárez no tenía ningún valor.

Los cuerpos de niñas y mujeres siguieron apareciendo, violados, mutilados, marcados, violentados; la zona comenzó a inundarse de cruces rosadas, las cuales comenzaron a ser colocadas por los familiares en los lugares donde habían sido hallados los cuerpos mancillados. No aparecían responsables, por el contrario:

2 En América Latina la desigualdad por razones de género y el machismo se encuentra profundamente institucionalizado, esto ha contribuido a que la región cuente con altos índices de ausentismo paterno y embarazo adolescente, razón por la cual las mujeres con frecuencia detentan la jefatura de hogar y crían solas a sus hijos e hijas. 
Las autoridades han omitido durante varios años información sobre sus averiguaciones o la han dado de manera parcial, incompleta y confusa, han actuado de manera ineficiente en la persecución de los delitos e incluso han debido liberar a algún presunto responsable quien fue objeto de tortura, y han propiciado una desconfianza generalizada frente a las instituciones (Lagarde, 2008, p. 213).

Pero en la medida en que se multiplicaban las víctimas, los familiares que consultaban el estatus de los casos o que presionaban exigiendo respuestas y justicia comenzaron a ser revictimizados: intimidaciones, amenazas, persecuciones y agresiones; las cuales también se extendieron a hacia investigadores, periodistas y activistas que comenzaban a indagar sobre la naturaleza de estos crímenes y sus involucrados. La negligencia, la inoperancia y la burocracia fue la norma en estos casos, lo que llevo a los familiares de las víctimas o victimas secundarias de los femicidios a redoblar los esfuerzos para visibilizarlos, buscar el apoyo de activistas y del movimiento feminista, de los medios de comunicación, así como, de organismos internacionales para que estos dejaran de ser considerados crímenes azarosos y hechos aislados.

Surgieron organizaciones de apoyo a familiares de las víctimas y de lucha frente a la violencia contra las mujeres, así como grupos de atención a víctimas que se manifestaron con fuerza como parte de movimientos civiles en defensa de los derechos humanos y de los movimientos de mujeres y feminista. A pesar de todo, los homicidios han continuado. De la denuncia local se pasó a la nacional y desde entonces, Ciudad Juárez es conocida en el mundo por los crímenes de niñas y mujeres, mediante intensas campañas para abatir la impunidad que los han acompañado. El feminicidio ha trascendido las fronteras mexicanas porque, con legítimo derecho, las organizaciones directamente vinculadas al proceso de justicia y al movimiento, han recurrido a organismos internacionales civiles e institucionales. Se han pronunciado al respecto, Amnistía 
Internacional, la Corte Interamericana de Derechos Humanos, el Parlamento Europeo, congresos de países europeos, como el Congreso de los Diputados de España, además del Congreso de los Estados Unidos, ayuntamientos de localidades de diversos países, ongs, redes de mujeres y muchos más (Lagarde, 2008, p. 209).

De este modo, fue en Ciudad Juárez donde se consolidaron los primeros movimientos sociales en contra de los asesinatos de mujeres por el hecho de ser mujeres, liderados por los familiares de las víctimas y posteriormente asumidos como bandera feminista. Estas movilizaciones públicas y colectivas comenzaron a ser replicadas en otras regiones de América Latina donde las mujeres también estaban siendo asesinadas de forma sistemática y cruel, entre estos El Salvador, Guatemala y Honduras.

Pero pese a su gravedad y recurrencia, esta problemática continuó siendo considerada como consecuencia de las particularidades, características y conflictos políticos, económicos y sociales de la región centroamericana, no como una problemática estructural en el contexto de una sociedad desigual. De este modo, los asesinatos sexistas y misóginos de niñas y mujeres durante los años noventa continuó siendo considerada por el resto de América Latina como ajena y lejana, como escena televisiva de pandillas, narcos y coyotes; situación que parecía no poder afectar a las mujeres blancas, clase media, profesionales y habitantes de las grandes urbes.

Es a partir de la década del 2000 que el femicidio comenzó a cobrar interés en otros países de América Latina debido a la ocurrencia de crímenes contra las mujeres muy mediatizados. Esto obligó a estas sociedades a hablar de la violencia contra la mujer perpetrada por hombres, pero ya no del estereotipo de mujeres maquilas asesinadas por coyotes en el desierto mexicano, sino de mujeres asesinadas en el contexto de la violencia de pareja, la explotación sexual y la trata por parte mafias, funcionarios policiales o desconocidos; así como, de los femicidios perpetrados en el contexto de ataque sexuales de niñas y mujeres sometidas en el transporte, 
de regreso desde el colegio, el trabajo, una fiesta, o cuando acudieron a alguna entrevista laboral que resultó ser falsa.

Estos hechos aunados a los avances obtenidos en el reconocimiento y rechazo de la violencia contra la mujer por parte de instancias internacionales, comenzaban a dar un marco de referencia para la comprensión y análisis de estos crímenes. Pero ante la ausencia de información y estadísticas oficiales y confiables algunas organizaciones de mujeres y articulaciones feministas universitarias comenzaron a sistematizar de forma independiente los asesinatos de mujeres que eran cometidos en sus países y que a nadie parecían importar.

Entre las primeras iniciativas es posible considerar el registro de femicidios de La Red Chilena contra la Violencia Doméstica y Sexual, el cual se realiza desde el año 2001 a partir de los casos reseñados en los medios de comunicación; a esta le seguiría el Observatorio Ciudadano Nacional sobre Feminicidio de México que construye una base de datos con los casos desde 2007 y el Observatorio de Femicidios "Adriana Marisel Zambrano" coordinado por la Asociación Civil La Casa del Encuentro en Argentina desde el año $2008^{3}$.

Pero es en el año 2006 con la traducción al español del libro Femicide. The politics of woman killing (La política del asesinato de las mujeres) de Diana Russell y Jill Radford, y del libro Femicide in Global Perspective (Femicidio: una perspectiva global) de Diana Russell y Roberta Harmes, que, pese a no estar tipificados, los asesinatos de mujeres por el hecho de ser mujeres,

\footnotetext{
3 Tras la tipificación del delito en diferentes países de América Latina las iniciativas de conformación de observatorios de femicidio comenzaron a incrementarse en la región, en algunos países donde no existen estadísticas sobre estos crímenes estos registros independientes se constituyen como la única fuente de información en la materia, mientras que en aquellos países donde si hay estadísticas oficiales y públicas, estos registros permiten visibilizar y contrarrestar las debilidades, deficiencias e inconsistencias de los registros gubernamentales.
} 
comenzaron a ser conocidos y conceptualizados como femicidio o feminicidio 4 en la región. Este término comenzó a popularizarse en México pues, esta definición parecía explicar los masivos y sistemáticos asesinatos de mujeres en Ciudad Juárez; pero también daba un marco de referencia para

${ }^{4}$ El término acuñado por su pionera Diana Russell es el de femicidio, este sería la denominación utilizada por Diana Russell y Jill Radford en el libro Femicide. The politics of woman killing y por Diana Russell y Roberta Harmes en el libro Femicide in Global Perspective, sin embargo, la confusión se inició en el año 2006 cuando la académica Marcela Lagarde (quien coordinó y presentó la edición en español de estos textos) tradujo y sustituyó femicide (femicidio) por feminicidio, arguyendo en el año 2008 que "en castellano femicidio es una voz homóloga a homicidio y sólo significa homicidio de mujeres", y atribuyéndose posteriormente el haber acuñado el término feminicidio. Ante este hecho Diana Russell se pronunciaría, afirmando: "Cuando me invitaron a un Seminario sobre femicidio en Juárez, México, en 2004, iniciado por una antropóloga feminista radical y congresista, Marcela Lagarde, ella me pidió permiso para traducir el femicidio al español como Feminicidio, consentido. Sin embargo, en 2006, Lagarde redefinió el feminicidio, agregando la siguiente cláusula a mi definición de femicidio de 2001 "la impunidad con la cual estos delitos se tratan típicamente en América Latina". Entiendo que Lagarde y sus partidarios ahora afirman que ella acuñó el término feminicidio. Pero no es legítimo considerar la redefinición de un término como constitutivo de acuñarlo. Además, una definición sólida debe evitar realizar la definición del fenómeno que se define, condicional a la reacción a él. Entonces, por ejemplo, si una esposa-agresora finalmente mata a su esposa porque ella quiere el divorcio, él sería culpable de femicidio. Sin embargo, si lo arrestan y lo declaran culpable de este crimen, entonces, según la definición de Lagarde, ya no es culpable de feminicidio porque el caso no fue tratado con impunidad. Esto demuestra por qué la definición revisada de feminicidio de Lagarde no cumple con el criterio de una definición sólida. Desafortunadamente, se ha desarrollado un conflicto muy destructivo en muchos países latinoamericanos en función de si las feministas allí han optado por adoptar los términos femicidio o feminicidio. Las feministas que han adoptado el feminicidio generalmente se niegan a trabajar con aquellas que han adoptado el femicidio, y viceversa. Espero sinceramente que esta desafortunada situación no se extienda a otros países" (Russell, 2012, sp). Desde mi perspectiva, como bien lo señalo en el libro Cultura femicida. El riesgo de ser mujer en América Latina, la modificación de la palabra femicide durante su traducción era innecesaria, puesto que el desarrollo de la categoría por parte de sus autoras pioneras explicitaba de forma clara y pedagógica el carácter y contenido del término; por lo cual, con independencia del significado literal que este pudiera tener en español, la definición y desarrollo del mismo permitía al lector aclarar cualquier duda surgida; por ello, "es presumible que, con la referida traducción, Marcela Lagarde pretendía el desarrollo de una categoría "paralela" que pudiera atribuírsele y que le permitiera escalar en el ámbito académico y mediático latinoamericano” (Pineda, 2019; p. 33). 
los asesinatos de mujeres que eran cometidos por sus parejas y ex parejas intimas, así como, por conocidos o desconocidos en el contexto de agresiones sexuales y otros motivos sexistas y misóginos en otras latitudes de América Latina.

Las denuncias, movilizaciones y presiones ante estos crímenes por parte de los familiares, organización de mujeres y académicas no disminuyeron, por el contrario, se multiplicaron y comenzaron a incluir en sus comunicaciones, declaraciones y consignas los términos femicidio y feminicidio. Estos hechos crearon las condiciones para que, aunque el delito aún no estuviese tipificado, estos crímenes comenzaran a ser contabilizados y sistematizados por los gobiernos de países como República Dominicana (2005) y Chile (2007).

Pero la magnitud, sistematicidad y crueldad de los femicidios, aunado a la demanda de la Comisión Interamericana de Derechos Humanos presentada contra los Estados Unidos Mexicanos el 4 de noviembre de 2007 relacionada con la supuesta responsabilidad internacional del Estado por "la desaparición y ulterior muerte” de las jóvenes Claudia Ivette González, Esmeralda Herrera Monreal y Laura Berenice Ramos Monárrez cuyos cuerpos fueron encontrados en un campo algodonero de Ciudad Juárez el día 6 de noviembre de 2001; sirvió como empuje para que México se planteara como el primer país de América Latina en diseñar y presentar un proyecto de ley para tipificar el femicidio, sin embargo, este fue continuamente postergado.

No obstante, con la demanda de la Comisión Interamericana de Derechos Humanos por el caso conocido como "Campo algodonero" comenzaba en la región una nueva etapa de reconocimiento legal de estos crímenes específicos contra las niñas y las mujeres. Esto sirvió de impulso a las demandas y exigencias de familiares, activistas, organizaciones de mujeres y académicas, las cuales ahora exigían a los gobiernos tipificar los crímenes que enlutaban hogares, comunidades, regiones y países. 
Sería Costa Rica el primer país de la región en tipificar los asesinatos de mujeres motivados por el sexismo y la misoginia en el año 2007 bajo la figura de femicidio; a este le seguirían Guatemala (Femicidio 2008), Chile (Femicidio 2010), El Salvador (Feminicidio 2011), Argentina (Homicidio agravado 2012), Nicaragua (Femicidio 2012), México (Feminicidio 2012), Bolivia (Feminicidio 2013), Panamá (Femicidio 2013), Perú (Feminicidio 2013), Honduras (Femicidio 2013), República Dominicana (Feminicidio 2014), Ecuador (Femicidio 2014), Venezuela (Femicidio 2014), Brasil (Feminicidio 2015), Colombia (Feminicidio 2015), Paraguay (Feminicidio 2016) y Uruguay (Femicidio 2017) ${ }^{5}$.

\section{Situación, movilización y acción ante el femicidio en la América Latina actual}

Tras la tipificación de los asesinatos sexistas y misóginos de las mujeres en la región bajo la figura de homicidio agravado, femicidio o feminicidio, se creaban las condiciones para que estos crímenes pudieran ser efectiva y eficientemente contabilizados, pero sobretodo, prevenidos y sancionados; no obstante, al año 2019, la realidad dista mucho de los compromisos asumidos por los Estados.

De los 18 países de América Latina que han tipificado los asesinatos de mujeres por el hecho de ser mujeres, 16 de ellos han contabilizado al menos en dos oportunidades estos crímenes; algunos realizan esta publicación de estadísticas de forma regular y han mejorado progresivamente la recopilación y análisis de los datos, entre ellos es posible mencionar Argentina, Chile, Costa Rica y Perú; otros han dejado de publicar esta información como es el caso de Colombia, Nicaragua y Venezuela; mientras que países como Brasil y Honduras ni siquiera cuentan con estadísticas para

\footnotetext{
${ }^{5}$ En lo que refiere a la tipificación del delito en América Latina, no existen diferencias sustantivas entre los términos femicidio y feminicidio; estando su empleo en un país u otro determinado por una mayor o menor influencia de alguno de los términos y el background al cual se ha tenido acceso en la materia.
} 
ningún año en la materia. Pese a ello, estas cifras oficiales de 16 países recopiladas desde los años 2005 a 2018 dan cuenta de la ocurrencia de 13438 femicidios en América Latina durante los últimos 14 años ${ }^{6}$.

6 Fuente: Argentina Cifras 2014-2017 Registro Nacional de Femicidios de la Justicia Argentina. Cifras 1 de enero y el 15 de noviembre de 2018 Observatorio de Femicidios de la Defensoría del Pueblo de la Nación. Bolivia: Rendición Pública de Cuentas Final presentada por el Fiscal General del Estado Plurinacional de Bolivia. Chile: Informes 2007-2015 Circuito Intersectorial de Femicidios. Cifras 2016-2018 Indicadores de Género del Instituto Nacional de Estadísticas de Chile. Colombia: Años 2009-2014 y 2016 Observatorio de asuntos de género (OAG) de la Consejería Presidencial para la Equidad de la Mujer. Cifras 2015 "Boletín Epidemiológico Violencia de Género en Colombia” del Instituto Nacional de Medicina Legal y Ciencias Forenses. Costa Rica: Cifras 2007-2018 Informes anuales "Mujeres fallecidas por femicidio en Costa Rica bajo el ámbito de la Ley de Penalización de la Violencia Contra las Mujeres y la Convención Interamericana Belem do Pará", del Observatorio de Violencia de Género Contra las Mujeres y Acceso a la Justicia del Poder Judicial de la República de Costa Rica. Ecuador: Subcomité Técnico de Validación de Femicidios de la Fiscalía General del Estado. El Salvador: Cifras 2013-2017 y primer semestre 2018 "Estado y situación de la violencia contra las mujeres en El Salvador" del Instituto Salvadoreño para el Desarrollo de la Mujer ISDEMU. Guatemala: Informes "Violencia en Contra de la Mujer 2008-2013" y "Estadísticas de Violencia en contra de la Mujer 2O14-2O17" Instituto Nacional de Estadística del Guatemala. México: Informe "Información sobre violencia contra las mujeres (incidencia delictiva y llamadas de emergencia 9-1-1" del Secretariado Ejecutivo del Sistema Nacional de Seguridad Pública de la Secretaria de Seguridad y Protección Ciudadana. Nicaragua: Informe de Gestión Anual 2013, 2014 y 2016 del Ministerio Público de Nicaragua. Panamá: Estadísticas 2014-2018 de femicidios registrados en la República de Panamá según Ministerio Público. Paraguay: Cifras 2011-2013 informe "Violencia contra las mujeres en Paraguay: avances y desafíos" del Ministerio de la Mujer en Paraguay y ONU Mujeres. Datos 2014-2016 extraídos del informe "Feminicidio en Paraguay: hecho punible de acción penal pública" de la Secretaria de Género de la Corte Suprema de Justicia. Cifras 2017-2018 Informe "Características de los casos de femicidio en el Paraguay año 2018" Observatorio de la Mujer del Ministerio de la Mujer MinMujer. Perú: "Estadísticas sobre feminicidio según las características de las víctimas y el presunto victimario 2009 - 2015" del Observatorio de Criminalidad del Ministerio Público. Cifras 2016 "Boletín V-2017 Feminicidios en el Perú" del Observatorio Nacional de Política Criminal "José Hurtado Pozo" del Ministerio de Justicia y Derechos Humanos. Cifras 2017 y 2018 Ministerio de la Mujer y Poblaciones Vulnerables (MIMP). República Dominicana: Informes 2013-2017 sobre los feminicidios en la Republica Dominicana de la Procuraduría General. Uruguay: Cifras 2012-2016 Informe "Femicidios íntimos en Uruguay. Homicidios a mujeres a manos de (ex) parejas" de la División Políticas de Género y el Observatorio de Violencia y Criminalidad del Ministerio del Interior. Cifras 2017 Informe de homicidios del 


\begin{tabular}{|c|c|c|c|c|c|c|c|c|c|c|c|c|c|c|c|}
\hline País & 2005 & 2006 & 2007 & \begin{tabular}{|l|}
2008 \\
\end{tabular} & 2009 & 2010 & 2011 & 2012 & 2013 & 2014 & 2015 & 2016 & 2017 & 2018 & Total \\
\hline Argentina & & & & & & & & & & 225 & 235 & 254 & 251 & 251 & 1216 \\
\hline Bolivia & & & & & & & & & 25 & 69 & 110 & 104 & 109 & 128 & 545 \\
\hline Chile & & & 61 & 59 & 55 & 49 & 40 & 34 & 40 & 40 & 45 & 34 & 44 & 42 & 543 \\
\hline Colombia & & & & & 104 & 125 & 130 & 139 & 88 & 145 & 81 & 128 & & & 940 \\
\hline Costa Rica & & & 21 & 33 & 39 & 31 & 42 & 26 & 18 & 24 & 27 & 26 & 26 & 24 & 337 \\
\hline Ecuador & & & & & & & & & & 27 & 55 & 69 & 108 & & 259 \\
\hline El Salvador & & & & & & & & & 98 & 178 & 358 & 350 & 332 & 173 & 1489 \\
\hline Guatemala & & & & 109 & 174 & 205 & 245 & 246 & 300 & 209 & 209 & 210 & 220 & & 2127 \\
\hline México & & & & & & & & & & & 411 & 600 & 742 & 894 & 2647 \\
\hline Nicaragua & & & & & & & & & 42 & 38 & 19 & 10 & & & 109 \\
\hline Panamá & & & & & & & & & & 26 & 29 & 19 & 18 & 19 & 111 \\
\hline Paraguay & & & & & & & 14 & 24 & 5 & 26 & 23 & 39 & 50 & 54 & 235 \\
\hline Perú & & & & & 154 & 139 & 123 & 122 & 111 & 100 & 103 & 105 & 116 & 149 & 1222 \\
\hline República Dominicana & 98 & 99 & 89 & 131 & 92 & 97 & 128 & 103 & 71 & 93 & 77 & 88 & 107 & & 1273 \\
\hline Uruguay & & & & & & & & 20 & 22 & 13 & 26 & 16 & 23 & 22 & 142 \\
\hline Venezuela & & & & & & & & & & & 121 & 122 & & & 243 \\
\hline Total & & & & & & & & & & & & & & & 13438 \\
\hline
\end{tabular}

Fuente: Elaboración propia

Ahora, si bien es cierto que la existencia y progresivo mejoramiento de estas estadísticas oficiales suponen un avance en la materia; las iniciativas de recolección y sistematización de casos de femicidios en la región desarrolladas por organizaciones de mujeres, observatorios de género, instituciones académicas y aquellas bases de datos consolidadas por individualidades ${ }^{7}$, reportan cifras más elevadas de ocurrencia del femicidio.

Estas estadísticas en oportunidades son disminuidas en los conteos oficiales por la existencia de diferencias metodológicas en la recolección y sistematización de la información, así como, por la actualización de las estadísticas como resultado de los procesos de investigación de los casos. Sin embargo, algunas de estas estadísticas suelen ser manipuladas y

Observatorio Nacional sobre Violencia y Criminalidad del Ministerio del Interior. Cifras enero-octubre 2018 Presentación de cifras anuales de violencia de género del Ministerio del Interior. Venezuela: Informes anuales de gestión del Ministerio Público.

7 Un ejemplo de ello es la investigadora María Salguero, quien por iniciativa propia y de forma voluntaria sistematiza, mapea y publica los casos de feminicidio en México desde enero del año 2016 hasta la actualidad. 
disminuidas por parte de los organismos gubernamentales de competencia con fines político-partidistas, para desviar la atención de los medios de comunicación, para desmovilizar a la población ante las demandas y reclamos sobre estos crímenes; pero también para ocultar la inoperancia estatal ante la gravedad del femicidio, su incapacidad para prevenirlo, para proteger a las mujeres, así como, para perseguir y condenar a los responsables.

Ante esta situación, la toma de conciencia de la población y las demandas en contra del femicidio se han masificado. Si bien estas movilizaciones se iniciaron como exigencias de información, investigación, persecución y sanción de los responsables por parte de las familias de las víctimas, en la actualidad la lucha contra el femicidio se ha convertido en una de las principales demandas del movimiento feminista; el mejor ejemplo de ello lo constituye la multitudinaria movilización realizada el 03 de junio de 2015 en ochenta ciudades de Argentina bajo la consigna "Ni una menos", y que desde entonces se extendería por toda América Latina.

No obstante, pese a que en los últimos años se ha avanzado en la tipificación del delito, la creación de una institucionalidad en la materia, aunado a la sistematización y publicación de estadísticas; esto no se ha traducido en políticas públicas de prevención de su ocurrencia, en la disminución del número de casos y menos aún en justicia para las víctimas. Sin embargo, pese a la lamentable situación, es importante reconocer los esfuerzos de los familiares de las víctimas, los movimientos de mujeres, académicas, investigadoras, periodistas, activistas e individualidades, quienes cada vez más se involucran en la denuncia y visibilización de estos crímenes, en su contabilización y divulgación, pero sobre todo, en la organización, movilización y presión dirigida contra las instancias de poder para el diseño, formulación y seguimiento de políticas públicas e iniciativas concretas que garanticen la prevención del femicidio; la disminución de sus índices de ocurrencia, la persecución y condena de sus perpetradores, así como, el 
otorgamiento de justicia para las niñas y mujeres a quienes por sexismo y misoginia les han sido arrebatadas sus vidas.

\section{Bibliografía}

CIDH. (16 de noviembre 2009) Sentencia caso González y otras ("Campo algodonero") Vs. México. Disponible en: https://bit.ly/1kho5vc

Gutiérrez, G. (2004) Violencia sexista. Algunas claves para la comprensión del feminicidio en Ciudad Juárez. Universidad Nacional Autónoma de México, México D.F.

Labrecque, M. (2005) "Justicia social, impunidad, condiciones de vida de las mujeres. Una comparación México-Canadá”. En: Femicidios e impunidad. Centro de encuentros cultura y mujer CECYM, Buenos Aires.

Lagarde, M. (2008) “Antropología, feminismo y política: violencia femicida y derechos humanos de las mujeres”. En: Retos teóricos y nuevas prácticas. Ankulegi Editores, Donostia.

Pineda, E. (2019) Cultura femicida. El riesgo de ser mujer en América Latina. Prometeo Libros, Buenos Aires.

Russell, D. (2006) "Feminicidio por arma de fuego: un año de crímenes de odio mortales en Estados Unidos". En: Feminicidio: una perspectiva global. Centro de investigaciones interdisciplinarias en Ciencias y Humanidades Universidad Nacional Autónoma de México, México D.F.

Russell, D. y Harmes, R. (2006) Feminicidio: una perspectiva global. Centro de investigaciones interdisciplinarias en Ciencias y Humanidades Universidad Nacional Autónoma de México, México D.F. 
Russell, D. y Radford, J. (2006) Feminicidio. La politica del asesinato de las mujeres. Centro de investigaciones interdisciplinarias en Ciencias y Humanidades Universidad Nacional Autónoma de México, México D.F. 